\section{Low-Temperature Crystallography: Conference in Oxford}

A CONFERENCE on low-temperature crystallography, organized jointly by the X-Ray Analysis Group of the Institute of Physics and the Low Temperature Group of the Physical Society, will be held in the Clarendon Laboratory, Oxford, during April 12-13. On the first day two sessions will be held on the following topics : physical problems in low-temperature erystallography (chairman, Dr. K. A. G. Mendelssohn), and X-ray methods and measurements at low temperatures (chairman, Prof. C. S. Barrett). The third, and last, session on April 13 will be devoted to a mixture of topics (chairman, H. P. Rooksby). On April 11, prior to the conference, the X-Ray Analysis Group will hold its annual general meeting, followed by a general discussion on the collection and classification of crystallographic data for doterminative and reference purposes. The meetings are open to all interested, a fee of one guinoa being charged to those who are not members of the Institute of Physics or the Physical Society. Registration forms and further information can be obtained from the Deputy Secretary, Institute of Physics, 47 Belgrave Square, London, S.W.1.

\section{Discontinuance of the Physical Society's Reprint \\ Scheme}

DURING the past three years the Physical Society has run a reprint scheme whereby members and subscribers could purchase reprints of individual papers published in the Society's Proceedings. A survey conducted at the end of the three years has shown, however, that only about 5 per cent of the members have utilized the service and that the scheme has proved very costly, of the order of $£ 600$ a year compared with about $£ 200$ income from the sale of reprints. Accordingly, the Society has regretfully decided to discontinue the scheme as from the beginning of this year and the publication of Abstracts Bulletin No. 38.

\section{Announcements}

Tre following elections have been made in the Paris Academy of Sciences: Prof. C. Bressou, director of the National Veterinary School of Alfort, to be a member of the Rural Economy Section in succession to the late Prof. M. Javillier; and Prof. F. van den Dungen, professor of analytical mechanies in the University of Brussels, to be correspondant for the Mechanics Section in succession to Prof. T. von Kármán, recently elected a foreign associate of the Academy.

THe Institution of British Agricultural Engineers is again offering two scholarships to candidates who are eligible for taking the final examination in 1957 for the National Diploma in Agricultural Engineering. The awards are the Farm Mechanization Scholarship (£100) of the Temple Press, Ltd., and the Dunlop Rubber Co., Ltd., Scholarship (£250), which is for a $_{0}$ university graduate wishing to obtain the Diploma as a specialist qualification. Application forms, to be returned by May 1, and further information can be obtained from the Secretary of the Institution at 6 Buckingham Gate, London, S.W.1.

THE Society for Psychical Research is offering a prize of fifty pounds for an essay of less than 3,000 words on one of the following topics : $(a)$ the best programme of research for the first one hundred hours of work with the next successful card-guessing subject discovered; the design should be supported by argument; (b) the best discussion of the logical and/or scientific implications of precognition, assuming this to be established statistically from the work of card-guessing subjects. Entries should be submitted under a pseudonym, and should be sent not later than October 1, 1956, to the Secretary, Society for Psychical Research, 31 Tavistock Square, London, W.C.1.

AWARDS are being offered from the Life Insurance Medical Research Fund of Australia and New Zealand, and as in previous years these will consist of grants-in-aid to non-profit institutions conducting medical research, fundamental or clinical, and research fellowships to medical graduates or those with equivalent scientific training for full-time research in problems broadly related to cardiovascular function and disease. The grants-in-aid are designed to cover all the financial requirements of a particular line of research and are usually $£ 1,000-£ 3,000$ a year for one to three years. The research fellowships may be taken up in Australia and New Zealand $(£ 1,800-£ 2,000)$ for one year initially, or may be travelling fellowships for two years abroad and a third year in Australia or New Zealand (£2,000$£ 2,250$ a year). Application forms for the awards, to be returned by July 1, and further information can be obtained from Dr. John H. Halliday, Medical Director, Life Insurance Medical Research Fund of Australia and New Zealand, 87 Pitt Street, Sydney, N.S.W.

The Royal Society of Medicine, Section of Experimental Medicine and Therapeuties, is arranging a symposium on "Anti-tumour Agents", to be held in the rooms of the Society on May 7. Two groups of anti-tumour drugs will be discussed, namely, cytostatic agents (such as the nitrogen mustards) and antimetabolites, from the point of view of their physico-chemical properties, metabolic reactions and anti-tumour activity for both experimental and human cancers. Further information can be obtained from Dr. T. M. Chalmers, The Middlesex Hospital, London, W.I.

A symposidm on "Corrosion Prevention in Packaging and Storage", organized by the Corrosion Group and the Birmingham and Midland Section of the Society of Chemical Industry, will be held during April 11-12 in the Chemistry Lecture Theatre of the University of Birmingham. Owing to the printingtrade dispute, it will be impossible to provide preprints of the papers; but summaries of all the papers and, where possible, complete copies of some of them will be sent to those registering for the symposium. Non-members of the Society can participate on payment of a fee of one guinea. Registration forms, to be returned by April 3, and further information can be obtained from the Assistant Secretary, Society of Chemical Industry, 56 Victoria Street, London, S.W.1.

Begrnning this year, the Physical Review will no longer reprint the programmes and abstracts of papers contained in the Bulletin of the American Physical Society. The Bulletin will be published as a separate journal eight times a year and will appear previous to each meeting of the Society, so as to contain the detailed programme and abstracts of all papers to be presented at the meeting. Abstracts that appear in the Bulletin will not necessarily be published in the Physical Review or in the Society's other publications. 